\title{
Patient perspectives in the management of asthma: improving patient outcomes through critical selection of treatment options
}

REVIEW

This article was published in the following Dove Press journal:

Patient Preference and Adherence

2 February 2010

Number of times this article has been viewed

\author{
Nicola Scichilone \\ Adele Contino \\ Giovanni Battista Figlioli \\ Giuseppe Paglino \\ Vincenzo Bellia \\ Dipartimento di Medicina, \\ Pneumologia, Fisiologia e Nutrizione \\ Umana (DIMPEFINU), University of \\ Palermo, Palermo, Italy
}

Correspondence: Nicola Scichilone

Dipartimento di Medicina, Pneumologia, Fisiologia e Nutrizione Umana

(DIMPEFINU), University of Palermo, via Trabucco 180, 90146 Palermo, Italy

$\mathrm{Tel}+39$ 09I 6802766

Fax +39 09| 6882165

Email n.scichilone@libero.it

\begin{abstract}
Asthma is a chronic inflammatory disorder of the airways that requires long-term treatment, the goal of which is to control clinical symptoms for extended periods with the least possible amount of drugs. International guidelines recommend the addition of an inhaled long-acting beta2-agonist (LABA) to a low- to medium-dose inhaled corticosteroid (ICS) when low doses of ICS fail to control asthma symptoms. The fixed combined administration of ICS/LABA improves patient compliance, reducing the risk of therapy discontinuation. The relative deposition pattern of the inhaled drug to the target site is the result of a complex interaction between the device used, the aerosol formulation and the patient's adherence to therapy. Different inhalation devices have been introduced in clinical practice over time. The new hydrofluoroalkane (HFA) solution aerosols allow for the particle size to be modified, thus leading to deeper penetration of the medication into the lung. The Modulite ${ }^{\circledR}$ technology allows for the manipulation of inhaled HFA-based solution formulations, such as the fixed beclomethasone/formoterol combination, resulting in a uniform treatment of inflammation and bronchoconstriction. The success of any anti-asthmatic treatment depends on the choice of the correct device and the adherence to therapy.
\end{abstract}

Keywords: asthma, therapy, inhalers, compliance

\section{Introduction}

Asthma is a chronic inflammatory disorder of the airways characterized by a variable degree of airway obstruction, which can reverse spontaneously or after treatment, and an underlying condition of exaggerated airway narrowing in response to external stimuli. The chronic features of the disease imply a long-term treatment to attain optimal control of the respiratory symptoms. Indeed, the goal of treatment is to achieve and maintain control of clinical symptoms for extended periods with the least possible amount of drugs.

Control of the disease is optimal when the patient presents with no diurnal or night-time symptoms, no limitation of daily activities including exercise, minimum use of beta2-agonists, and no need for hospitalization. According to epidemiological observations, a variable proportion of the asthmatic population does not control the disease because of factors that include inadequate drug treatment, and lack of adherence to the recommended drug therapy or to the device. In addition, physicians and patients tend to underestimate the intensity and frequency of symptoms, and the need to monitor the disease. The occurrence of inadequate physician-patient communication also contributes to the lack of optimal control. As already cited, the lack of adherence to therapy strongly impacts on the control of the disease. Cramer et $\mathrm{al}^{1}{ }^{\text {demonstrated that }}$

submit your manuscript | www.dovepress.con 
the frequency of drug administration influences adherence to treatment, decreasing from $87 \%$ with one administration per day to $39 \%$ when four administrations per day are requested. Long-term treatment as a factor affecting adherence to treatment was shown in a 1-year study conducted in adults and children: ${ }^{2}$ at the end of the study, only $15 \%$ of patients was still receiving inhaled treatment regularly. Above all, it appears pertinent to state that drugs don't work in patients who don't take them!

Several epidemiological studies have been conducted in an effort to determine whether asthma control is attainable and in what proportion of patients. The AIRE (Asthma Insights and Reality in Europe) study, ${ }^{3}$ conducted on a sample of 2803 patients to examine the management of asthma in Europe, showed that despite the existence of highly effective treatments, frequent daytime and nocturnal symptoms and limitations of daily activities are reported by patients, including a high frequency of requests for unscheduled doctor visits, emergency department visits, and hospitalization for serious exacerbations. The ISAYA study ${ }^{4}$ confirmed that the inappropriate use of drugs is mainly responsible for failure to control asthma. This study found that $47 \%$ of persistent asthmatics that participated in the survey in Italy were using combination therapy that was inadequate for the severity level (too low a dosage of corticosteroids and/or inappropriate treatment), and that $64 \%$ of asthmatics were on an irregular treatment that should have been taken daily. The study confirmed that for each degree of severity, regularity of treatment was associated with better control of symptoms.

In evaluating whether optimal asthma control is attainable with current therapeutic options, the GOAL study ${ }^{5}$ showed that asthma control can be reached in a high percentage of patients, and this occurs more frequently when a regimen is implemented based on the degree of severity. The study provided evidence that the salmeterol/fluticasone combination is more effective than treatment with fluticasone alone in achieving good asthma control. Of particular importance is the finding that the salmeterol/fluticasone combination was able to control symptoms more quickly and at a lower dose of corticosteroid. The observed improvements in several clinical and functional parameters were clinically relevant and sustained over time, stressing the importance of regular and prolonged treatment.

\section{Inhaled therapy in asthma}

The cornerstone of the daily control of asthma is inhaled therapy. In this respect, direct delivery of the aerosolized drug in the lower airways is advocated to treat inflammation and to relieve obstruction. In comparison with oral therapy, the inhaled pathway allows the minimization of effective doses and consequently minimization of adverse systemic effects, particularly important for long-term treatments often necessary in asthma. On the other hand, several variables affect the inhaled pathway, mostly related to the drug formulation and delivery device. Pharmacological treatment of asthma requires a stepwise approach based on the severity of the disease, which can be adapted continuously according to the clinical control of the disease. The ultimate goal of treatment is to achieve and maintain control of clinical symptoms for extended periods with the least possible amount of drugs.

Inhaled glucocorticosteroids (ICS) represent first-line treatment for the management of asthma, in that they are the most effective anti-inflammatory medications for the treatment of persistent symptoms (Table 1). Most studies have demonstrated their efficacy in controlling airway inflammation, ${ }^{6}$ reducing symptoms, improving quality of life and lung function, decreasing airway hyper-responsiveness, ${ }^{7}$ reducing frequency and severity of exacerbations, ${ }^{8}$ and reducing asthma mortality. ${ }^{9}$ International guidelines recommend the addition of an inhaled long-acting beta2-agonist (LABA) to a low- to medium-dose ICS when low doses of ICS fail to control asthma symptoms. ${ }^{10}$ Randomized clinical trials with LABA in combination with corticosteroids have demonstrated that the addition of LABA to ICS is more beneficial in terms of asthma control and pulmonary function than increasing the dose of ICS alone. ${ }^{11-14}$ When administered as fixed combination, the administration of ICS/LABA has been demonstrated to improve patient compliance, thus

Table I Effects of glucocorticoids on the pathogenic mechanisms of airway inflammation

Inhibit the production of proinflammatory cytokines

Reduce the number of mast cells, eosinophils, and other inflammatory cells of the airways

Increase the beta2-adrenergic receptor responsiveness of the airways to sympathomimetic agents

Modulate the synthesis of IgE in allergic-atopic subjects

Interfere with the biosynthesis of eicosanoids

Reduce nitric oxide production

Inhibit neurogenic inflammation

Prevent the activation and migration of inflammatory cells

Reduce vasodilation of the microcirculation and thus the edema

by plasma exudation

Reduce the production of mucus 
reducing the risk of therapy discontinuation, ${ }^{15}$ compared to the administration of these components separately. There is evidence suggesting that LABA and ICS mutually potentiate their effects when given in combination. ${ }^{16}$

The aim of inhaled therapy is to allow the medication to reach the target site. This can be attained by ensuring the penetration of the aerosolized particles into the lower respiratory tract, and the deposition of the drug along the respiratory tract. Obviously, the deposition of the drug should translate into functional and clinical benefits. Taken together, these conditions also require the right choice of device. ${ }^{17}$ The relative deposition pattern of the inhaled drug is the result of a complex interaction between the aerosol formulation and the device used. A body of histological and functional evidence has accumulated to confirm that the distal airways are the predominant site of airway inflammation in asthma; ${ }^{18-21}$ therefore, the distal airways represent the main target of treatment (Figure 1), and the distribution of the drug along the bronchial tree should translate into higher efficacy of the inhaled therapy and reduced rate of adverse events. Most importantly, similar clinical benefit can be attained with a lower dose of the drug. ${ }^{22}$

The devices differ in terms of technical design (required inspiratory flow rate, actuation), composition (characteristics of the propellant, carrier substances), dose per inhalation, and costs. In addition, producers have made major efforts to make devices more user-friendly. The pressurized

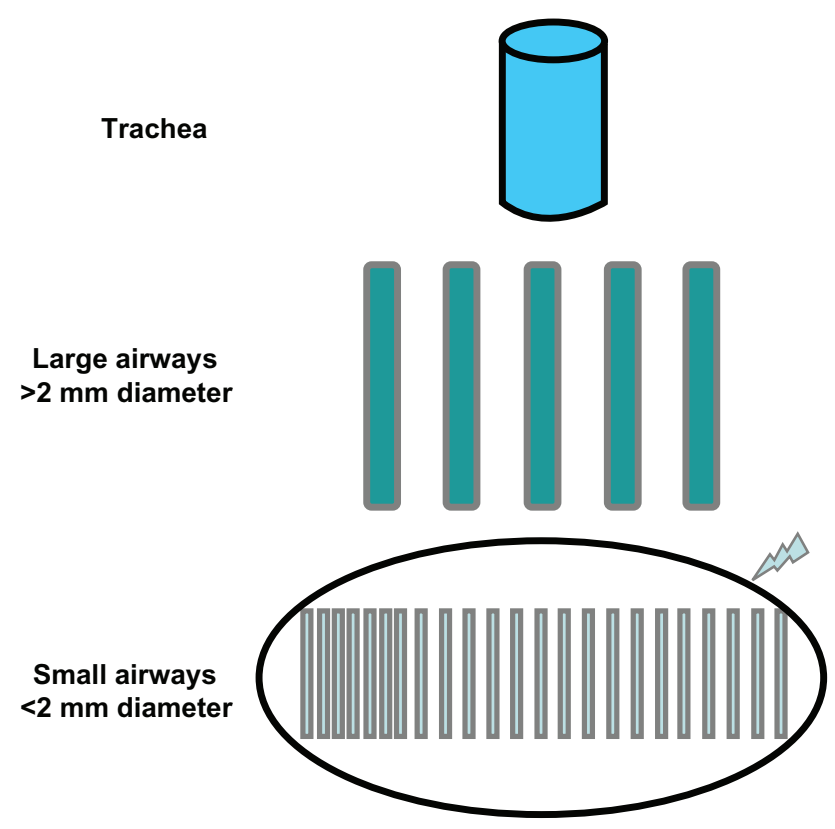

Figure I Schematic of the bronchial tree with emphasis on the peripheral district, which is the main target of anti-asthmatic treatment. metered dose inhaler (pMDI) is the most widely used device. ${ }^{23}$ The major issue with the use of pMDIs is that the aerosol is fast-moving, which increases the risk of drug deposition in the pharynx, and therefore occurrence of local side-effects with limited clinical efficacy. The drug contained in the MDI canister is formulated as a suspension or solution, formulations which have different properties in terms of particle size, plume velocity and duration, as well as user friendliness, which affect drug delivery to the appropriate site. In the suspension formulation, the active drug is insoluble in the propellant and remains as solid powder; therefore, suspension formulations need to be shaken before inhalation to allow uniform distribution of solid powder particles of the drug. It has been demonstrated that a significant proportion of patients do not shake the device properly or present with coordination problems, ${ }^{24}$ resulting in variable amounts of drug emitted in each aerosol puff. The occurrence of mistakes associated with the inhalation procedures can be reduced by regular training and follow-up. Other devices include breath-actuated pMDIs (BA-pMDI), such as Autohaler ${ }^{\circledR}$ and Easi-Breathe ${ }^{\circledR}$, which incorporate a mechanism activated during inhalation that triggers the metered-dose inhaler. Dry powder inhalers (DPIs) do not need coordination, as the drug is not driven by the propellant but is delivered by the inhalation effort. However, the actuation of the device needs high inspiratory flow to assure optimal drug delivery, ${ }^{25}$ which is crucial in the elderly. Indeed, Janssens and colleagues ${ }^{26}$ recently demonstrated that, in elderly patients, the ability to generate sufficient inspiratory flow across a dry powder inhaler is compromised, irrespective of the presence of chronic obstructive pulmonary disease (COPD). Three types of DPIs are available with different handling instructions: single dose $\left(\right.$ Handihaler $^{\circledR}$, Aerolizer $^{\circledR}$ ), multiple doses (Diskus $^{\circledR}$ ) and reservoir (Turbohaler ${ }^{\circledR}$ ). An official document on device selection and outcomes of aerosol therapy based on current literature reported that, when selecting a device for patients with asthma and COPD, the following should be considered: device/drug availability, patient age and the ability to use the selected device correctly, device use with multiple medications, and physician and patient preference. ${ }^{27}$ Evidence-based guidelines for the device selection conclude that no difference between devices in any efficacy outcome has been recorded, provided that patients use the correct technique for inhalation. Therefore, the selection criteria should be related mainly to patient age, preference and ability to use the selected device correctly. Table 2 describes the main properties of each device. 
Table 2 Description of the main properties of different devices

\begin{tabular}{lll}
\hline Type & Advantages & Limitations \\
\hline $\begin{array}{ll}\text { Pressurized metered dose } \\
\text { inhaler (pMDI) }\end{array}$ & Portable & Need for coordination \\
& Accepted in emergencies & Not suitable for children \\
Used for different compounds & High deposition in the pharynx \\
Dry powder inhaler (DPI) & Portable & Need for high inspiratory flow \\
& Actuation by inhalation & Not suitable for children \\
& Less need for coordination & Not acceptable in emergencies \\
& Used for different compounds & Negative effect of humidity on the drug \\
& & Variable deposition in the pharynx \\
Nebulizer & No need for coordination & Difficult to carry \\
& No need for maximal inspiratory & Long inhalation sessions \\
& maneuvers & Hygiene and maintenance issues \\
& Suitable for all ages & Possible degradation of the active drug \\
& Accepted in emergency situations & (ultrasound) \\
& Allows for oxygen supplementation & Variation in the amount of inhaled drug \\
\end{tabular}

\section{The Modulite ${ }^{\circledR}$ technology and the beclomethasone dipropionatel formoterol combination}

Since the 1987 Montreal Protocol that abolished chlorofluorocarbon (CFC) use in inhalers investigated, a hydrofluoroalkane propellant (HFA-134a) was developed as a nonozone-depleting CFC-free alternative for use in pMDI. The limits of the pMDI (difficulty to coordinate, low lung deposition, high oral deposition, need of a spacer) are not present in HFA inhalers, which are largely accepted by patients. ${ }^{28}$ Studies comparing beclometasone HFA with CFC inhalers showed no difference in terms of adverse events (oral thrush and hoarse voice).$^{28}$ The new HFA solution aerosols allow for the particle size to be modified, thus leading to deeper penetration of the medication into the lung. ${ }^{29}$ Recently, a new technology of the HFA solution pMDI has been developed: ${ }^{30}$ the Modulite $^{\circledR}$ (Chiesi Ltd) platform technology allows for the manipulation of inhaled HFA-based solution formulations. This technology offers the advantage of matching the CFC-based pMDIs with the HFA-MDIs on a 1:1 nominal dose ratio basis, thus favoring the transition to CFC-free formulations. Switching from CFC-MDI to HFA-MDI has been achieved successfully for corticosteroids ${ }^{31}$ and bronchodilators. ${ }^{32}$ Recently, the HFA-propelled extra-fine fixed combination formulation of beclometasone dipropionate/formoterol (BDP/F) 100/6 $\mu \mathrm{g}$ $\left(\right.$ Foster $\left.^{\circledR}\right)$ delivered via pMDI has been developed with the Modulite $^{\circledR}$ technology. The BDP/F HFA pMDI combination is an extra-fine formulation, in which BDP dose is 2.5-fold lower than the conventional BDP CFC product (100 $\mu \mathrm{g}$ of BDP per actuation instead of $250 \mu \mathrm{g}$ of nonextra-fine BDP). Furthermore, because of the small particle size of BDP/F, the two active drugs are delivered to both central and peripheral airways, resulting in a uniform treatment of inflammation and bronchoconstriction. The reduction in BDP dose lowers the amount of drug deposited in the upper airway, potentially improving the efficacy/safety ratio. Therefore, the optimized drug deposition that results from reduced particle size may lead to improved clinical benefit, as shown by Huchon et al. ${ }^{33}$ The slower velocity and the longer duration of the plume reduce the throat deposition and improve the lung deposition of the drug.

\section{Clinical efficacy and safety of beclomethasone/formoterol combination}

A body of literature has demonstrated the efficacy and safety of both beclomethasone and formoterol separately and as fixed combination treatment, as reviewed by Nicolini et al, ${ }^{34}$ and by Fabbri et al. ${ }^{35}$ The efficacy of the BDP/F fixed combination was evaluated in a 3-month randomized controlled trial conducted in patients with moderate asthma who were still symptomatic despite receiving low-dose ICS. ${ }^{36} \mathrm{BDP} / \mathrm{F}$ given as one inhalation twice daily improved lung function by more than a double equipotent dosage of BDP nonextrafine. In patients with severe asthma, ${ }^{36} \mathrm{BDP} / \mathrm{F}$ given as two inhalations twice daily for 6 months showed improvement in peak expiratory flow and forced expiratory volume in 1 second comparable to that of an equipotent nonextra-fine regimen of $\mathrm{BDP}$ and formoterol administered via separate inhalers, and was more effective than $1000 \mu \mathrm{g} /$ day BDP nonextra-fine. Importantly, the BDP/F fixed combination was superior to both BDP plus formoterol in separate inhalers and BDP monotherapy in terms of clinical measures of asthma control, suggesting that patients receiving extra-fine 
$\mathrm{BDP} / \mathrm{F}$ may experience additional benefits to functional improvements.

Two studies with similar results ${ }^{37,38}$ were conducted to assess the efficacy and tolerability of BDP/F vs budesonide/ formoterol (BUD/F) and fluticasone propionate/salmeterol (FP/S), respectively. In the first study, ${ }^{38}$ patients who were taking BDP/F as two inhalations twice daily showed similar improvement in lung function, asthma symptoms and percentage of days without the use of rescue medication to that obtained with an equipotent regimen of $\mathrm{BUD} / \mathrm{F}$ $200 / 6 \mu \mathrm{g}$ administered as two puffs twice daily. Interestingly, $\mathrm{BDP} / \mathrm{F}$ demonstrated similar onset of action to that of $\mathrm{BUD} / \mathrm{F}$. In the second study, ${ }^{37} \mathrm{BDP} / \mathrm{F}$ was compared with fluticasone propionate/salmeterol (FP/S) pMDI 125/25 $\mu \mathrm{g}$, both administered as two puffs twice daily, and lung function improved similarly in both arms. In this study, the $\mathrm{BDP} / \mathrm{F}$ group had a faster onset of bronchodilation as opposed to the FP/S group. This is of great importance, based on the fact that patients ask for immediate relief of symptoms, and this can drastically improve adherence to treatment and, consequently, asthma control. Of note, a greater improvement in forced vital capacity was shown in the BDP/F group, suggesting a greater effect on peripheral airways.

\section{Patient perspectives and outcomes}

Asthmatic patients are worried about three different aspects of the disease: asthmatic exacerbations, management of symptoms, and management of the disease during an exacerbation-free period. Even if asthmatic exacerbations could be the most important event in a patient's life, the impact of asthma on everyday life could be an important factor also when asthma is asymptomatic. For the patient, the way of approaching emerging health-related problems depends on the severity of the clinical manifestations as well as on the strategies that are used to solve them (coping strategies) and on previous experiences. Different studies have clearly confirmed a weak correlation between the magnitude of airway obstruction and the severity of asthmatic symptoms. ${ }^{39}$

It is therefore important to understand needs and expectations of asthmatic patients in order to obtain optimal disease management. Several surveys ${ }^{40,41}$ note that these patients have little information about their asthma and they live with diurnal and nocturnal symptoms. Moreover, these studies emphasize that patients are not completely satisfied with physician behavior. Moreover, patients often do not trust pharmacological treatment, and they are not convinced that therapy can completely control asthmatic symptoms.
Nowadays, effective diagnostic and therapeutic tools are widely available. In chronic diseases such as asthma, diagnosis and therapy are not sufficient to obtain the improvement of health status. In fact, adherence to therapy, although often underestimated, is necessary to obtain optimal control of asthma; proper management of therapy is probably more useful then expensive investments to improve current therapies. Nonadherence may involve up to $20 \%$ of patients who need treatment for a short period (10 days) because of an acute disease, up to $50 \%$ of patients affected by a chronic symptomatic disease, and up to $70 \%$ of those affected by a chronic asymptomatic disease. Coping strategies, which represent the way patients face the disease, determine individual differences in the psychological reactions towards asthma, ${ }^{42-45}$ which in turn influence the adherence to treatment and quality of life.

Nonadherence can occur in only one phase of the treatment (eg, a patient takes drugs regularly but does not change their life-style, for example, they do not quit smoking); or it can occur in different phases of treatment (eg, some patients are more adherent to therapy during weekends than weekdays). Moreover, patients may spontaneously stop therapy to verify their recovery and efficacy of treatment. Nonadherence has some consequences for patients and their relatives, for the health system and for society. The consequences of nonadherence are shown in Table 3.

\section{Several different factors reduce \\ adherence to therapy}

1. Factors related to treatment: ${ }^{46,47}$ complex medical treatment that requires the use of different drugs; the complexity of dosage and the different devices used for inhalation therapy; the side effects of medications.

2. Factors related to the patient: age; low perception of the disease; personal ideas about treatment; cognitive or physical impairments; psychological or psychiatric disorders; absence of family or social support; financial difficulties; the refusal to accept the disease.

3. Factors related to the health system organization: difficult admission to medical facilities; health welfare discontinuation; high costs for patients.

4. Factors related to the relationship between physicians and patients: ${ }^{48}$ ineffective communication; inadequate patient or doctor behavior; inability to understand the patient perspectives on disease and treatment.

Different strategies can improve adherence to therapy. ${ }^{49}$ These can be summarized as follows: improve patientphysician communication, simplify the therapeutic plan 
Table 3 Consequences of nonadherence

Low control of symptoms
Negative effects on quality of life
Loss of working or school-days
Increase in disability
Progression of the disease
Unjustified use of drugs, often with relevant side effects
More unplanned medical examinations
More frequent hospitalizations

(if possible reduce the number of daily doses, using the simplest and most effective inhalator devices), and reduce the waiting lists. As stated by Juniper ${ }^{50}$ both the clinician and the patient decide on the patient's management plan, by negotiating a plan that the patient is willing to follow. A contractual agreement between patient and clinician may improve both clinical asthma control and patient healthrelated quality of life.

\section{Conclusions}

Treatment of asthma aims at achieving and maintaining control of symptoms by using inhaled LABA and ICS. The fixed combined administration of ICS/LABA improves patient compliance, thus reducing the risk of therapy discontinuation. The optimal control of asthma depends on the drug selected, the device used, and the elimination of factors that reduce patient adherence to therapy. Inhalers differs in their delivery technique, their efficiency, and their ease of use. The new aerosol technologies allow for the particle size to be modified, thus leading to deeper penetration of the medication into the lung. How a patient approaches the different components of the disease depends on the strategies they use to cope with them, which is why international asthma guidelines stress that before making changes to a patient's therapy their compliance and inhaler technique should be checked. Adherence to treatment can be considered as the final result of interactions among the patient, the disease, the treatment, and the health system organization.

\section{Disclosures}

The authors declare no conflicts of interest.

\section{References}

1. Cramer JA, Mattson RH, Prevey ML, Scheyer RD, Ouellette VL. How often is medication taken as prescribed? A novel assessment technique. JAMA. 19899;261(22):3273-3277.

2. Breekveldt-Postma NS, Koerselman J, Erkens JA, van der Molen T, Lammers JW, Herings RM. Treatment with inhaled corticosteroids in asthma is too often discontinued. Pharmacoepidemiol Drug Saf. 2008;17(4):411-422.
3. Vermeire PA, Rabe KF, Soriano JB, Maier WC. Asthma control and differences in management practices across seven European countries. Respir Med. 2002;96(3):142-149.

4. De Marco R, Cazzoletti L, Cerveri I, Corsico A, Bugiani M, Accordini S, et al. Are the asthma guideline goals achieved in daily practice? A populationbased study on treatment adequacy and the control of asthma. Int Arch Allergy Immunol. 2005;138(3):225-234.

5. Bateman ED, Boushey HA, Bousquet J, Busse WW, Clark TJ, Pauwels RA, et al. Can guideline-defined asthma control be achieved? The Gaining Optimal Asthma ControL study. Am J Respir Crit Care Med. 2004;170(8):836-844.

6. Jeffery PK, Godfrey RW, Adelroth E, Nelson F, Rogers A, Johansson SA. Effects of treatment on airway inflammation and thickening of basement membrane reticular collagen in asthma. A quantitative light and electron microscopic study. Am Rev Respir Dis. 1992;145(4 Pt 1):890-899.

7. Juniper EF, Kline PA, Vanzieleghem MA, Ramsdale EH, O'Byrne PM, Hargreave FE. Effect of long-term treatment with an inhaled corticosteroid (budesonide) on airway hyperresponsiveness and clinical asthma in nonsteroid-dependent asthmatics. Am Rev Respir Dis. 1990;142(4): 832-836.

8. Pauwels RA, Lofdahl CG, Postma DS, Tattersfield AE, O'Byrne P, Barnes PJ, et al. Effect of inhaled formoterol and budesonide on exacerbations of asthma. Formoterol and Corticosteroids Establishing Therapy (FACET) International Study Group. $N$ Engl J Med. 1997;337(20): 1405-1411.

9. Suissa S, Ernst P, Benayoun S, Baltzan M, Cai B. Low-dose inhaled corticosteroids and the prevention of death from asthma. N Engl J Med. 2000;343(5):332-336.

10. Global INitiative for Asthma (GINA). Global strategy for asthma management and prevention:NHLBI/WHO workshop report. National Heart, Lung and Blood Institute, Bethesda, MD. Updated 2006.

11. Bateman ED, Bantje TA, Joao Gomes M, Toumbis MG, Huber RM, Naya I, et al. Combination therapy with single inhaler budesonide/ formoterol compared with high dose of fluticasone propionate alone in patients with moderate persistent asthma. Am J Respir Med. 2003;2(3): 275-281.

12. Lalloo UG, Malolepszy J, Kozma D, Krofta K, Ankerst J, Johansen B, et al. Budesonide and formoterol in a single inhaler improves asthma control compared with increasing the dose of corticosteroid in adults with mild-to-moderate asthma. Chest. 2003;123(5):1480-1487.

13. Ringdal N, Eliraz A, Pruzinec R, Weber HH, Mulder PG, Akveld M, et al. The salmeterol/fluticasone combination is more effective than fluticasone plus oral montelukast in asthma. Respir Med. 2003;97(3):234-241.

14. Tal A, Simon G, Vermeulen JH, Petru V, Cobos N, Everard ML, et al. Budesonide/formoterol in a single inhaler versus inhaled corticosteroids alone in the treatment of asthma. Pediatr Pulmonol. 2002;34(5):342-350.

15. Rosenhall L, Borg S, Andersson F, Ericsson K. Budesonide/formoterol in a single inhaler (Symbicort) reduces healthcare costs compared with separate inhalers in the treatment of asthma over 12 months. Int J Clin Pract. 2003;57(8):662-667.

16. Barnes PJ. Asthma. New therapeutic approaches. Br Med Bull. 1992;48(1):231-247.

17. Brocklebank D, Wright J, Cates C. Systematic review of clinical effectiveness of pressurised metered dose inhalers versus other hand held inhaler devices for delivering corticosteroids in asthma. $B M J$. 2001;323(7318):896-900

18. Battaglia S, den Hertog H, Timmers MC, Lazeroms SP, Vignola AM, Rabe KF, et al. Small airways function and molecular markers in exhaled air in mild asthma. Thorax. 2005;60(8):639-644.

19. Bourdin A, Paganin F, Prefaut C, Kieseler D, Godard P, Chanez P. Nitrogen washout slope in poorly controlled asthma. Allergy. 2006; 61(1):85-89.

20. in 't Veen JC, Beekman AJ, Bel EH, Sterk PJ. Recurrent exacerbations in severe asthma are associated with enhanced airway closure during stable episodes. Am J Respir Crit Care Med. 2000;161(6):1902-1906. 
21. Wagner EM, Liu MC, Weinmann GG, Permutt S, Bleecker ER Peripheral lung resistance in normal and asthmatic subjects. Am Rev Respir Dis. 1990;141(3):584-588.

22. Pritchard JN. The influence of lung deposition on clinical response. JAerosol Med. 2001;14 Suppl 1:S19-S26.

23. Virchow JC, Crompton GK, Dal Negro R, Pedersen S, Magnan A, Seidenberg J, et al. Importance of inhaler devices in the management of airway disease. Respir Med. 2008;102(1):10-19.

24. Giraud V, Roche N. Misuse of corticosteroid metered-dose inhaler is associated with decreased asthma stability. Eur Respir J. 2002;19(2):246-2451.

25. Tarsin WY, Pearson SB, Assi KH, Chrystyn H. Emitted dose estimates from Seretide Diskus and Symbicort Turbuhaler following inhalation by severe asthmatics. Int J Pharm. 2006;316(1-2):131-137.

26. Janssens W, VandenBrande P, Hardeman E, De Langhe E, Philps T, Troosters T, et al. Inspiratory flow rates at different levels of resistance in elderly COPD patients. Eur Respir J. 2008;31(1):78-83.

27. Dolovich MB, Ahrens RC, Hess DR, Anderson P, Dhand R, Rau JL, et al. Device selection and outcomes of aerosol therapy: Evidencebased guidelines: American College of Chest Physicians/American College of Asthma, Allergy, and Immunology. Chest. 2005;127(1): 335-371.

28. Vanden Burgt JA, Busse WW, Martin RJ, Szefler SJ, Donnell D. Efficacy and safety overview of a new inhaled corticosteroid, QVAR (hydrofluoroalkane-beclomethasone extrafine inhalation aerosol), in asthma. J Allergy Clin Immunol. 2000;106(6):1209-1226.

29. Goldin JG, Tashkin DP, Kleerup EC, Greaser LE, Haywood UM, Sayre JW, et al. Comparative effects of hydrofluoroalkane and chlorofluorocarbon beclomethasone dipropionate inhalation on small airways: assessment with functional helical thin-section computed tomography. J Allergy Clin Immunol. 1999;104(6):S258-S267.

30. Acerbi D, Brambilla G, Kottakis I. Advances in asthma and COPD management: delivering CFC-free inhaled therapy using Modulite technology. Pulm Pharmacol Ther. 2007;20(3):290-303.

31. Thongngarm T, Silkoff PE, Kossack WS, Nelson HS. Hydrofluoroalkane134A beclomethasone or chlorofluorocarbon fluticasone: effect on small airways in poorly controlled asthma. J Asthma. 2005;42(4): 257-263.

32. Houghton CM, Langley SJ, Singh SD, Holden J, Monici Preti AP, Acerbi D, et al. Comparison of bronchoprotective and bronchodilator effects of a single dose of formoterol delivered by hydrofluoroalkane and chlorofluorocarbon aerosols and dry powder in a double blind, placebo-controlled, crossover study. Br J Clin Pharmacol. 2004;58(4):359-366.

33. Huchon G, Magnussen H, Chuchalin A, Dymek L, Gonod FB, Bousquet J. Lung function and asthma control with beclomethasone and formoterol in a single inhaler. Respir Med. 2009;103(1):41-49.

34. Nicolini G, Scichilone N, Bizzi A, Papi A, Fabbri LM. Beclomethasone/ formoterol fixed combination for the management of asthma: patient considerations. Ther Clin Risk Manag. 2008;4(5):855-864.
35. Fabbri LM, Nicolini G, Olivieri D, Papi A. Inhaled beclometasone dipropionate/formoterol extra-fine fixed combination in the treatment of asthma: evidence and future perspectives. Exp Opin Pharmacother. 2008;9(3):479-490.

36. Dhillon S, Keating GM. Beclometasone dipropionate/formoterol: in an HFA-propelled pressurised metered-dose inhaler. Drugs. 2006;66(11):1475-1483; discussion 84-85.

37. Papi A, Paggiaro P, Nicolini G, Vignola AM, Fabbri LM. Beclomethasone/ formoterol vs fluticasone/salmeterol inhaled combination in moderate to severe asthma. Allergy. 2007;62(10):1182-1188.

38. Papi A, Paggiaro PL, Nicolini G, Vignola AM, Fabbri LM. Beclomethasone/ formoterol versus budesonide/formoterol combination therapy in asthma. Eur Respir J. 2007;29(4):682-689.

39. Apter AJ, Affleck G, Reisine ST, Tennen HA, Barrows E, Wells M, et al. Perception of airway obstruction in asthma: sequential daily analyses of symptoms, peak expiratory flow rate, and mood. J Allergy Clin Immunol. 1997;99(5):605-612.

40. Holgate ST, Price D, Valovirta E. Asthma out of control? A structured review of recent patient surveys. BMC Pulm Med. 2006;6 Suppl 1:S2.

41. Konings E, Dubois-Arber F, Narring F, Michaud PA. Identifying adolescent drug users: results of a national survey on adolescent health in Switzerland. J Adolesc Health. 1995;16(3):240-247.

42. Miles JF, Garden GM, Tunnicliffe WS, Cayton RM, Ayres JG. Psychological morbidity and coping skills in patients with brittle and non-brittle asthma: a case-control study. Clin Exp Allergy. 1997;27(10):1151-1159.

43. Aalto AM, Harkapaa K, Aro AR, Rissanen P. Ways of coping with asthma in everyday life: validation of the Asthma Specific Coping Scale. J Psychosom Res. 2002;53(6):1061-1069.

44. Adams RJ, Smith BJ, Ruffin RE. Factors associated with hospital admissions and repeat emergency department visits for adults with asthma. Thorax. 2000;55(7):566-573.

45. Adams S, Pill R, Jones A. Medication, chronic illness and identity: the perspective of people with asthma. Soc Sci Med. 1997;45(2):189-201.

46. Barber N, Parsons J, Clifford S, Darracott R, Horne R. Patients' problems with new medication for chronic conditions. Qual Saf Health Care. 2004;13(3):172-175.

47. Claxton AJ, Cramer J, Pierce C. A systematic review of the associations between dose regimens and medication compliance. Clin Ther. 2001;23(8):1296-1310.

48. Fuertes JN, Mislowack A, Bennett J, Paul L, Gilbert TC, Fontan G, et al. The physician-patient working alliance. Patient Educ Couns. 2007;66(1):29-36.

49. Corsico AG, Cazzoletti L, de Marco R, Janson C, Jarvis D, Zoia MC, et al. Factors affecting adherence to asthma treatment in an international cohort of young and middle-aged adults. Respir Med. 2007;101(6):1363-1367.

50. Juniper EF. The impact of patient compliance on effective asthma management. Curr Opin Pulm Med. 2003;9 Suppl 1:S8-S10.
Patient Preference and Adherence

\section{Publish your work in this journal}

Patient Preference and Adherence is an international, peer-reviewed, open access journal focusing on the growing importance of patient preference and adherence throughout the therapeutic continuum. Patient satisfaction, acceptability, quality of life, compliance, persistence and their role in developing new therapeutic modalities and compounds to

\section{Dovepress}

optimize clinical outcomes for existing disease states are major areas of interest. This journal has been accepted for indexing on PubMed Central. The manuscript management system is completely online and includes a very quick and fair peer-review system. Visit http://www.dovepress.com/ testimonials.php to read real quotes from published authors. 